\title{
Factors Associated with Low Uptake of Voluntary Medical Male Circumcision as HIV-Prevention Strategy among Men Aged I8-49 Years from Nyanza District, Rwanda
}

This article was published in the following Dove Press journal: HIVIAIDS - Research and Palliative Care

\author{
Pascal Nzamwital,2 \\ Emmanuel Biracyaza (iD) ${ }^{1,3}$ \\ 'Department of Community Health, \\ School of Public Health, University of \\ Rwanda, Kigali, Rwanda; ${ }^{2}$ Department of \\ Prevention, ADIS Healthcare Foundation \\ (AHF) Rwanda, Kigali, Rwanda; ${ }^{3}$ District \\ Manager of Sociotherapy Programme, \\ Prison Fellowship Rwanda (PFR), Kigali, \\ Rwanda
}

Background: Voluntary medical male circumcision (VMMC) is an effective biomedical intervention against HIV in developed and developing countries. However, there is low uptake of VMMC due to various factors, which hinders achievement of health-policy goals to increase uptake. Numerous campaigns offering the procedure free of charge exist in developing countries, but such initiatives seem to bear little fruit in attracting men to these services. This study assessed risk factors associated with the low uptake of VMMC among men in Nyanza district, Southern Province, Rwanda.

Methods: A cross-sectional study was conducted among adult males in Nyanza. A total of 438 men participated in individual interviews. Bivariate and multivariate logistic regression models were used with $95 \%$ confidence intervals and $p \leq 0.05$ was taken as statistically significant.

Results: Our results indicated that a low update of VMMC was highly prevalent $(35.8 \%)$. A majority (84.7\%) of participants had heard about VMMC, its complications, advantages in preventiing penile cancer, sexually transmitted infections, and HIV, condom use after circumcision, abstinence for 6 weeks after circumcision, and improving penile hygiene. Religion and education were significant factors in low uptake. Catholics were less likely to undergo VMMC than Muslims (OR 7.19, 95\% CI 1.742-29.659; $p=0.01$ ). Those of other faiths were less likely to undergo VMMC than Muslims (OR 6.035, 95\% CI 1.731-21.039; $p=0.005)$. Participants with secondary education were less likely to undergo VMMC than those with primary education only (OR $1.4,95 \%$ CI $0.74-2.64 ; p=0.03$ ). Having no formal education decreased the odds of being uncircumcised (OR 0.37 , 95\% CI $0.14-0.977$; $p=0.045$ ) when compared to those with primary education.

Conclusion: Uptake of VMMC remains low in Nyanza, but most men had sufficient knowledge about it. Education, religion, and marital status were major factors in the low uptake. Programs targeting peer influences and parents need to be prioritized.

Keywords: low uptake, VMMC, HIV/AIDS, prevention, men, adult, male circumcision

\section{Background}

HIV/AIDS) is a public health burden worldwide. Strategies to prevent and treat such diseases as HIV/AIDS, malaria, tuberculosis, hepatitis, Ebola, and other communicable diseases remain an unfinished public health agenda of the UN's Sustainable Development Goals and World Health Organization (WHO). ${ }^{1,2}$ To achieve this goal of promoting health through prevention of behavioral risks leading to HIV/AIDS, different health-care
Correspondence: Pascal Nzamwita Department of Community Health, University of Rwanda

Tel +250-78-959-8040

Email nzpasci@yahoo.fr 
interventions have been developed on a global scale. The Joint United Nations Programme on HIV/AIDS (UNAIDS) and the WHO recommend the implementation of safe voluntary medical male circumcision (VMMC)as an appropriate health strategy for preventing HIV/AIDS and other sexually transmitted infections (STIs). ${ }^{3}$ Studies have indicated that communities that use voluntary medical male circumcision (VMMC) effectively are more likely to have low rates of HIV than those that do not. $^{4-6}$

Accessibility of VMMC in most countries, particularly in low- and middle-income countries, is influenced by religious, sociocultural, and medical factors. Low accessibility of VMMC remains in many countries of the world, and this is a grave public health concern in low- and middle-income countries. Implementation of VMMC has been reported to be a serious health problem among elders acting as guardians of community culture. Studies have documented that VMMC is an effective intervention against HIV infection - $60 \%{ }^{7}$ Data show that $80 \%$ (20.3 million) had been provided VMMC intervention by 2015. Implementation has taken place in African countries with HIV prevalence. It is expected that 3.4 million new VMMCs could prevent the spread of HIV in the period 2015-2025. ${ }^{8}$

Studies conducted in Kenya, Uganda, and Tanzania have demonstrated that the prevalence of HIV/AIDS differs by community. Low sociodemographic status, age, residence, religion, and marital status are the main factors associated with this barriers to the prevention and treatment of STIs. ${ }^{9,10}$ HIV is a public health concern in eastern and southern African countries, and it is highly prevalent in communities not providing VMMC programs. ${ }^{6,11}$ Moreover, the household's be collectively reduced, taking into account the different involvement, having the circumcised friend or relative as well as being encouraged by the friend or family relative were found to be the cause of accessing to the VMMC. ${ }^{12}$ Factors driving low uptake of VMMC are fear of losing family revenue, fear of pain, and fear of receiving wounds. 4

Studies conducted in the US have shown a strong association between preference for VMMC and high socioeconomic status, whereas low uptake is associated with low socioeconomic status. In contrast, demographic and health surveys in sub-Saharan African countries have shown no consistent association with socioeconomic status. ${ }^{13}$ For example, in Tanzania, higher rates of circumcision were observed among men with higher levels of education, higher socioeconomic status, and living in urban areas, whereas in Lesotho circumcision was a public health burden among men with no education, in the lowest wealth quartile, and living in rural areas. $^{14}$ The same factors were assessed for determining why the uptake was low. The more males possess adequate knowledge regarding VMMC and the burdens of HIV/AIDS, the more they become motivated to get circumcised. Many factors may be associated with low uptake and high prevalence of STIs. Intervening factors are those that may influence uptake indirectly when other factors play an important role in pursuing MMC for the purpose of HIV prevention. ${ }^{15}$

The growing problem on which this study focuses is how to increase MC uptake as an HIV-prevention strategy, given the high prevalence of HIV infection, a pressing challenge in the health sector. ${ }^{4}$ One of the greatest impediments to $\mathrm{MC}$ uptake following HIV outbreaks is community reluctance to pursue otherinterventions for the prevention of heterosexually acquired HIV infection in men when HIV prevalence is high. ${ }^{3,11,16}$ Long distance to health facilities, fear of pain, biased information from health facilities, discouragement from friends, long healing period, and mandatory HIV testing before $\mathrm{MC}$ is carried out are factors associated with low uptake. $^{4}$ How to address these attitudes and behaviours while encouraging healthy ones and increase MC uptake has thus become a difficult task.

To reduce HIV infection among communities, it is generally contended that prevention strategies require important supplementary approaches for the anticipation of heterosexually acquired HIV infections in men in regions where HIV prevalence is high. ${ }^{7,17}$ In this regard, the current discourse points to solutions delivered and built from partner initiatives. ${ }^{5}$ Notably, the particular role of VMMC is a commonly understood medical technique that has been approved by the WHO as an additional prevention strategy against HIV. ${ }^{18}$ Empirical investigation in this regard is thus worth undertaking, notably in Rwanda, where the culture does not favor MC. ${ }^{19}$ VMMC is considered part of a comprehensive HIV-prevention package for heterosexually acquired infections in men. ${ }^{20}$ It is a cost-effective HIV-prevention measure, and largescale uptake of VMMC in populations with high HIV prevalence and a low circumcision rate has a considerable impact on the HIV epidemic and provides a cost-effective strategy. ${ }^{19,20}$ VMMC performed by welltrained clinicians among traditionally noncircumcising communitiesprevents HIV transmission by up to $60 \%{ }^{21}$ 
Nyanza is one of the eight districts of Rwanda's Southern Province, and has low uptake of VMMC when compared to other provinces (17.3\%). It has the second-highest HIV prevalence after Kigali (3.2\%). Nyanza has high STI prevalence on a national level, is eighth in HIV prevalence nationally, has a low MC rate $(15 \%)$, and VMMC uptake is the lowest nationwide. ${ }^{22}$ Althoughthe accessibility of VMMC in Nyanza is very low, little is known about factors influencing its uptake. This study is unique in that population from the target studies area. The results of the current study will be important in designing appropriate strategies to reinforce
VMMC uptake with the objective of long-term impact on HIV control in Nyanza. Building on the aforementioned literature, this study aimed to determine the prevalence and risk factors contributing to the low uptake of VMMC in Nyanza.

\section{Conceptual Framework}

Figure 1 shows a conceptual framework that indicates the relationships among mainly independent and outcome variables. The framework of this study was designed using prior studies documenting that VMMC is associated with factors categorized into three classes namely: sociodemographic
Independent variables

\section{A. Socio demographic}

variables:

Age, marital status, religion, type of residence, level of education, employment status, monthly income

\section{Outcome variable}

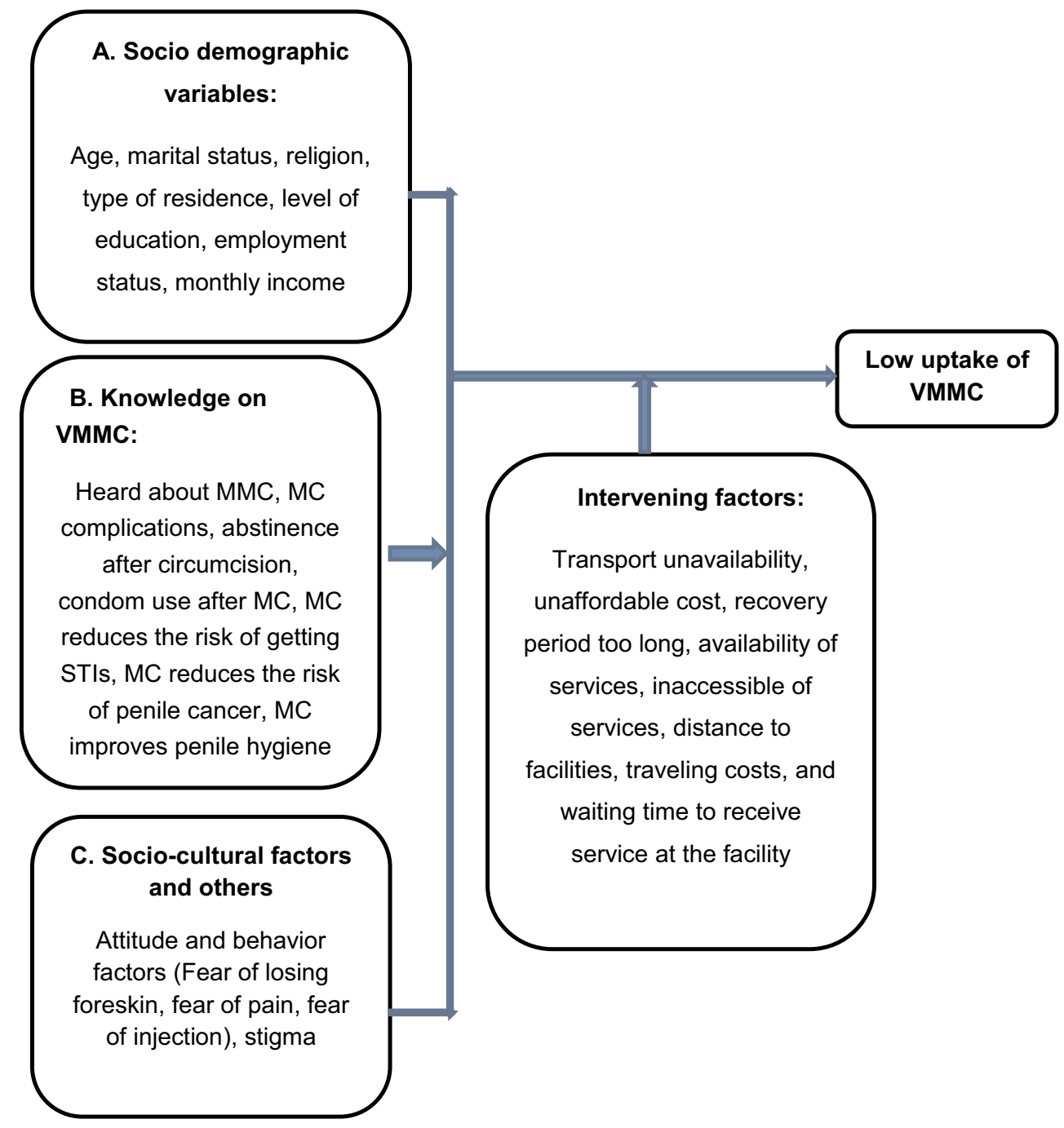

Figure I Conceptual framework of variables used in this study, ie, independent, intervening and outcome variables. We usedthree classes of independent variables. (A) Sociodemographic variables were age, education, area ofresidence, religion, marital status, and monthly income. (B) Knowledge on VMMC comprised subjects having heard about VMMC, MC complications, abstinence after circumcision, condom use after MC, MC reducing the risk of STIs and penile cancer, and improving penile hygiene. (C) socio-cultural factors and other factors including attitudes and behavior regarding MC (fear of losing foreskin, fear of pain, and stigma). Intervening variables were accessibility of services, availability of services, distance from household to health facility, transport, cost, and recovery period. The outcome variable was low uptake of VMMC.

Abbreviations: MC, male circumcision; VMMC, medical male circumcision; STls, sexually transmited infections. 
variables (age, education, residence, religion, marital status, and monthly income), knowledge on VMMC(heard about it, $\mathrm{MC}$ complications, need for abstinence and Mcondom use after $\mathrm{MC}$, reduction of risk of getting STIsand penile cancer, and improvement in penile hygiene), and other factors, including attitudes and behavior regarding $\mathrm{MC}$ (fear of losing foreskin, phobia of pain and stigma). Intervening variables are accessibility of services, availability of services, distance from household to health facility, transport, unaffordability, and recovery period too long.

\section{Methods}

\section{Study Design}

The study design used was a cross-sectional survey among males aged 18-49years in Nyanza district, Southern Province, Rwanda.

\section{Study Settings and Participants}

Nyanza has low MC prevalence (17.1\%) compared to other provinces of Rwanda. It has 17 health facilities: Nyanza District Hospital and 16 health centers where VMMC is carried out. It covers $672 \mathrm{~km}^{2}$. The population of Nyanza is 323,719, (166,069 female and 157,650 males), among which 73,514 males comprised our study population. Nyanza has the highest prevalence of STIs nationwide $18 \%$. It is also has the eighth-highest of HIV prevalence nationwide $(3.1 \%)$ and low coverage of MC $(15 \%){ }^{22}$

The target group for the study was all men 18-49 years old present in Nyanza at the time of data collection, whether they lived in Nyanza or not. The eligibility criterion was no severe psychiatric history that could affect participation. Those unwilling toor provide consent were excluded.

\section{Study Variables}

The dependent variable was uptake of VMMC. Independent variables were sociodemographic characteristics (age, marital status, residence, monthly income, religion, and education), knowledge on VMMC (heard about it, complications related to the operation, reduction in risk of penile cancer, improvement in penile hygiene, reduction of risk of catching STIs, and abstinence required after VMMC).

\section{Sample Size and Sampling}

For-sample size calculation, we used Yamane's formula. ${ }^{23}$ $n=\frac{N}{1+N e^{2}}=\frac{73514}{1+73514 x(0.05)^{2}}=397.8 \approx 398$, where $N$ is the target population (males aged 18-49 years), $n$ the size of the sample, and e the margin error $(5 \%$ or 0.05$)$. We added
Table I Sectors of Nyanza

\begin{tabular}{|l|l|c|c|}
\hline & & Residents Aged 18-49 Years & Sample \\
\hline 1 & Busasamana & 11,167 & 67 \\
2 & Busoro & 7,616 & 44 \\
3 & Cyabakamyi & 4,562 & 28 \\
4 & Kibirizi & 6,984 & 41 \\
5 & Kigoma & 7,618 & 45 \\
6 & Mukingo & 12,542 & 75 \\
7 & Muyira & 7,646 & 46 \\
8 & Ntyazo & 5,883 & 35 \\
9 & Nyagisozi & 5,498 & 33 \\
10 & Rwabicuma & 3,998 & 24 \\
\hline \multicolumn{2}{|l|}{ Total } & $\mathbf{7 3 , 5 1 4}$ & $\mathbf{4 3 8}$ \\
\hline
\end{tabular}

Notes: Fourth Rwanda Population and Housing Census, 2012 (NISR).

5\% to the minimum sample size (398 respondents) for participants who might not take part for such reasons as withdrawal. Therefore, the total sample size was 438 .

Using all sectors of Nyanza that had a higher rate of population than the other seven remaining sectors, the study population was disproportionally recruited from that population.We used stratified and simple random sampling for indicating the sample of each stratum the formula. The sample was proportionally divided according to the population of each sector of Nyanza. A structured questionnaire was used for data collection. Investigators were based at health centers where we expected many recruits to meeting the inclusion criteria, and data were collected for 2 weeks (September 2-16, 2019). Table 1 indicates the sample size for each sector (stratum), computed using the of Bluman's formula: ${ }^{24}$

$$
\begin{aligned}
n= & N S_{1}+N S_{2}+N S_{3}+N S_{4}+N S_{5}+N S_{6}+N S_{7}+N S_{8} \\
& +N S_{9}+N S_{10}
\end{aligned}
$$

$n s=\frac{N_{1} x n}{N}$, where $n$ is the sample size of the stratum, $N S$ the total population of each sector (stratum), and $N$ the general population of the whole district.

\section{Data Collection and Procedures}

Simple random sampling was used in data collection and the structured questionnaire was utilized. Data collectors attended 2 days of training on the data-collection process and materials for data collection. The questionnaires used was adopted from previous research on knowledge of VMMC and validated by the investigators in a pilot study in Gasabo, Remera. After collecting data from the pilot, the investigators adjusted questions for better comprehension. Data collected were coded, entered into SPSS 24 to be analyzed, then stored on an external 
disk. Completed questionnaires were kept in a closed cupboard to maintain confidentiality. Data were stored electronically, and password-protected software was used according to University of Rwanda rules and regulations regarding research. The time taken to complete the questionnaire was 20-30 minutes.

\section{Data Analysis}

Data were entered into Excel, categorized, then analyzed using SPSS 24. Both descriptive and analytical analyses were performed. In the descriptive analysis, frequencies and percentages were computed to summarize the sociodemographic characteristics of the participants. Based on MC prevalence, descriptive statistics were compiled and frequencies and proportions calculated. For knowledge on VMMC, participants who had answered at least four of the questions correctly were considered to have sufficient knowledge. Descriptive statistics were also computed and frequencies and proportions derived. Bivariate logistic regression was performed to indicated factors associated with VMMC uptake. Binary logistic regression analysis was performed to determine associations between dependent and independent variables. Independent variables with $p<0.2$ on bivariate logistic regression were fitted to binomial multivariate logistic regression analyses that utilized both full models, and reduced models were used with ORs to determine factors associated with VMMC uptake. Binomial multivariate regression was applied to identify the factors contributing to low VMMC uptake. Associated factors in the full model were exported to the reduced models. Statistical significance established as $p<0.05$.

\section{Ethics}

This study was carried out in accordance with the Declaration of Helsinki ${ }^{25,26}$ Ethics approval was sought from the Institutional Review Board, College of Medicine and Health Sciences (IRB, CMHS), University of Rwanda $\left(\mathrm{N}^{0}: 425 /\right.$ CMHS IRB/2019). After receiving this clearance, the local leaders authorized the researchers to carry out the study. Participants were informed of the purpose of the study, that there was no compensation, and asked if they would consent. They were able to withdraw from the study any time, and were informed that they would not be penalized for doing so. Confidentiality and privacy were ensured throughout the research. The right to autonomy and self-determination were taken into consideration throughout. The study team explained to the interviewees that the information wouldwas for research purposes only and would not be shared. Researcher, data collector and participants singed consent forms. Questionnaires were anonymous, numbered in order of evaluation, and did not contain identifiers of the participants.

\section{Results}

\section{Sociodemographic Characteristics}

A total of 438 participants were enrolled: $>67 \%$ were married, and 20.3\% aged 23-27 years. A majority (83.3\%) had attended at least primary school, and $>87 \%$ were Catholic. A majority (81.3\%) unemployed, students, or neither selfemployed nor employed (“others"), with $89.1 \%$ reporting low monthly incomes $(<\mathrm{RWF} 50,000)$ and $96.8 \%$ residing in Nyanza (Table 2).

Table 2 Sociodemographic Characteristics $(n=438)$

\begin{tabular}{|c|c|c|}
\hline Characteristics & $\begin{array}{c}\text { frequency } \\
\text { (n) }\end{array}$ & $\%$ \\
\hline \multicolumn{3}{|l|}{ Age } \\
\hline 18-22 years & 49 & 11.2 \\
\hline 23-27 years & 89 & 20.3 \\
\hline $28-32$ years & 73 & 16.7 \\
\hline $33-37$ years & 87 & 19.9 \\
\hline $38-42$ years & 85 & 19.4 \\
\hline 43 years and above & 55 & 12.6 \\
\hline \multicolumn{3}{|l|}{ Marital status } \\
\hline Single & 125 & 28.5 \\
\hline Married & 294 & 67.1 \\
\hline Separated/divorced & 19 & 4.3 \\
\hline \multicolumn{3}{|l|}{ Religion } \\
\hline Catholic & 382 & 87.2 \\
\hline Muslim & 13 & 3 \\
\hline Other & 43 & 9.8 \\
\hline \multicolumn{3}{|l|}{ Education } \\
\hline Primary & 365 & 83.3 \\
\hline Secondary and higher & 53 & 12.1 \\
\hline Illiterate & 20 & 4.6 \\
\hline \multicolumn{3}{|l|}{ Employment } \\
\hline Unemployed, student, and other & 356 & 81.3 \\
\hline Self-employed & 45 & 10.3 \\
\hline Employed & 37 & 8.4 \\
\hline \multicolumn{3}{|l|}{ Monthly income (RWF) } \\
\hline Below 50,000 & 391 & 89.3 \\
\hline $50,000-100,000$ & 38 & 8.7 \\
\hline 100,000 and above & 9 & 2.1 \\
\hline \multicolumn{3}{|l|}{ Area of residence } \\
\hline Nyanza & 424 & 96.8 \\
\hline Outside Nyanza & 14 & 3.2 \\
\hline
\end{tabular}




\section{Prevalence of VMMC Uptake by}

\section{Sociodemographic Characteristics}

VMMC uptake was $35.8 \%$, and varied based on sociodemographic status. The highest VMMC uptake (7.5\%) was found in those aged 33-37 years. Concerning marital status, the highest VMMC uptake was found in those who were married. Similarly, there was high VMMC uptake among respondents who were Catholic. In sum, $53.7 \%$ of uncircumcised participants had attended primary school, and there was high VMMC uptake among the unemployed, students, and others. More than $53.2 \%$ had monthly incomes $<$ RWF $50,000,>62 \%$ were residents of Nyanza (Table 3).

Table 3 Uptake of VMMC by Sociodemographic Characteristics

\begin{tabular}{|c|c|c|c|c|}
\hline \multirow[t]{2}{*}{ Characteristics } & \multicolumn{2}{|c|}{$\begin{array}{l}\text { Circumcised } \\
\qquad(n=\mid 57)\end{array}$} & \multicolumn{2}{|c|}{$\begin{array}{l}\text { Uncircumcised } \\
\qquad(n=28 I)\end{array}$} \\
\hline & $\mathbf{n}$ & $\%$ & $\mathbf{n}$ & $\%$ \\
\hline \multicolumn{5}{|l|}{ Age } \\
\hline $18-22$ years & 17 & 3.9 & 32 & 7.3 \\
\hline $23-27$ years & 32 & 7.3 & 57 & 13.0 \\
\hline $28-32$ years & 28 & 6.4 & 45 & 10.3 \\
\hline $33-37$ years & 33 & 7.5 & 54 & 12.3 \\
\hline $38-42$ years & 24 & 5.5 & 61 & 13.9 \\
\hline $43-49$ years & 23 & 5.3 & 32 & 7.3 \\
\hline \multicolumn{5}{|l|}{ Marital status } \\
\hline Single & 39 & 8.9 & 86 & 19.6 \\
\hline Married & 114 & 26.0 & 180 & $4 I .1$ \\
\hline Separated/divorced & 4 & 0.9 & 15 & 3.4 \\
\hline \multicolumn{5}{|l|}{ Religion } \\
\hline Catholic & 127 & 29.0 & 255 & 58.2 \\
\hline Muslim & 9 & 2.1 & 4 & 0.9 \\
\hline Other & 21 & 4.8 & 22 & 5.0 \\
\hline \multicolumn{5}{|l|}{ Education } \\
\hline Primary & 130 & 29.7 & 235 & 53.7 \\
\hline Secondary and higher & 15 & 3.4 & 38 & 8.7 \\
\hline Illiterate & 12 & 2.7 & 8 & 1.8 \\
\hline \multicolumn{5}{|l|}{ Employment } \\
\hline $\begin{array}{l}\text { Unemployed, student, and } \\
\text { other }\end{array}$ & 123 & 28.1 & 233 & 53.2 \\
\hline Self-employed & 18 & 4.1 & 27 & 6.2 \\
\hline Employed & 16 & 3.7 & 21 & 4.8 \\
\hline \multicolumn{5}{|l|}{ Monthly income (RWF) } \\
\hline Below 50,000 & 138 & 31.5 & 253 & 57.8 \\
\hline $50,000-100,000$ & 15 & 3.4 & 23 & 5.3 \\
\hline 100,000 and above & 4 & 0.9 & 5 & 1.1 \\
\hline \multicolumn{5}{|l|}{ Area of residence } \\
\hline Nyanza & 149 & 34.0 & 275 & 62.8 \\
\hline Outside Nyanza & 8 & 1.8 & 6 & 1.4 \\
\hline
\end{tabular}

\section{Knowledge-Level Variables}

A large majority (95.7\%) of participants had heard about circumcision in different settings. In sum, $92.5 \%$ those circumcised knew that one needed to abstain from sexual activity for 6 weeks after the circumcision operation, and $89 \%$ mentioned the need for condom use after the operation. A large majority (97\%) were aware of VMMC and indicated that they knew it was a medical operation that reduced the risks of catching STIs, including HIV, $89.7 \%$ of indicated that they knew VMMC contributed to reducing the risk of developing penile cancer, and $98.9 \%$ responded that VMMC was important for improving penile hygiene. Though some complications like infections, insufficient foreskin removal, and excessive foreskin removal are rare following circumcision, a majority ( $82 \%$ ) answered that bleeding was the most complication. A majority (84.7\%) were knowledgeable about VMMC (Table 4).

\section{Knowledge Level by Sociodemographic Characteristics}

Participants' knowledgedifferently varied based on sociodemographic status. Among knowledgeable participants, $19.5 \%$ were aged $33-37$ years and $38 \%-42 \%$, respectively, whereas among participants who were not knowledgeable, a majority were aged 18-22 years. A majority of participants were married (61\%), while single men represnted $8 \%$ of the sample. A majority (78.1\%) of those knowledgeable about VMMC were Catholic. The Among participants who were knowledgeable, a majority (71.2\%) had had a primary education only, while among the unknowledgeable, $12.1 \%$ had had a primary education only. A majority $(75.1 \%)$ of those knowledgeable about VMMC were unemployed, students, and others. Among participants not knowledgeable about MC, a majority (8\%) were self-employed. Among knowledgeable participants, a majority (77.4\%) had monthly incomes <RWF50,000, and among the unknowledgeable, this figure was $11.9 \%$. The results also demonstrated that a majority $(83.6 \%)$ of the knowledgeable resided in Nyanza (Table 5).

\section{Bivariate Analysis of VMMC Uptake}

Bivariate logistic analysis indicated that marital status, residence, age, monthly income, employment status, and being knowledgeable about VMMC were not significantly associated with being uncircumcised. Significant associations were found between circumcision and 
Table 4 Knowledge-level Variables

\begin{tabular}{|l|c|c|}
\hline Variables & $\mathbf{n}$ & $\%$ \\
\hline Heard about VMMC & & \\
Yes & 419 & 95.7 \\
No & 19 & 4.3 \\
\hline Need to abstain for 6 weeks after circumcision & & \\
Yes & 405 & 92.5 \\
No & 33 & 7.5 \\
\hline Need for condom use after VMMC & & \\
Yes & 390 & 89.0 \\
No & 48 & 11.0 \\
\hline VMMC reduces the risk of STDs & & \\
Yes & 425 & 97.0 \\
No & 13 & 3.0 \\
\hline VMMC reduces the risk of penile cancer & & \\
Yes & 393 & 89.7 \\
No & 45 & 10.3 \\
\hline VMMC improves penile hygiene & & \\
Yes & 433 & 98.9 \\
No & 5 & 1.1 \\
\hline VMMC causes complications & 27 & 6.2 \\
Infection & 359 & 82.0 \\
Bleeding & 26 & 5.9 \\
Excessive foreskin removed & 16 & 3.7 \\
I do not know & 371 & 84.7 \\
\hline Knowledge about VMMC & 10.3 \\
Knowledgeable & 5105 \\
\hline Not knowledgeable & $59 x$ \\
\hline
\end{tabular}

Abbreviations: VMMC, voluntary medical male circumcision; STDs, sexually transmitted diseases.

religion, as well as education. On bivariate analysis, religion was a significant predictor of low VMMC uptake. Being Catholic was significantly associated with low VMMC uptake. Similarly, educational was a significant factor in low VMMC uptake (Table 6).

\section{Multivariate Analysis of VMMC Uptake}

On multiple logistic regression, religion and education were also significantly associated with low VMMC uptake.Being Catholic increased the likelihood of low VMMC uptake compared to Muslims (OR 7.19, 95\% CI (1.742-29.659; $p=0.01)$. Followers of other religions were less likely to have low VMMC uptake thanMuslims (OR 6.035, 95\% CI 1.731-21.039; $p=0.005)$. Those with no formal education were less likely to have low VMMC uptake of than those with primary education. (OR 0.37 ,
Table 5 Knowledge by Sociodemographic Characteristics

\begin{tabular}{|c|c|c|c|c|}
\hline \multirow[t]{2}{*}{ Variables } & \multicolumn{2}{|c|}{$\begin{array}{c}\text { Knowledgeable } \\
(n=37 I)\end{array}$} & \multicolumn{2}{|c|}{$\begin{array}{c}\text { Not } \\
\text { Knowledgeable } \\
(n=67)\end{array}$} \\
\hline & $\mathbf{n}$ & $\%$ & $\mathbf{n}$ & $\%$ \\
\hline \multicolumn{5}{|l|}{ Age } \\
\hline $18-22$ years & 8 & 1.8 & 41 & 9.4 \\
\hline $23-27$ years & 77 & 17.6 & 12 & 2.7 \\
\hline 28-32 years & 66 & 15.1 & 7 & 1.6 \\
\hline $33-37$ years & 84 & 19.2 & 3 & 0.7 \\
\hline $38-42$ years & 81 & 18.5 & 4 & 0.9 \\
\hline 43 years and above & 55 & 12.6 & 0 & 0 \\
\hline \multicolumn{5}{|l|}{ Marital status } \\
\hline Single & 90 & 20.5 & 35 & 8.0 \\
\hline Married & 267 & 61 & 27 & 6.2 \\
\hline Separated/divorced & 14 & 3.2 & 5 & I.I \\
\hline \multicolumn{5}{|l|}{ Religion } \\
\hline Catholics & 342 & 78.1 & 40 & 9.1 \\
\hline Muslim & 10 & 2.3 & 3 & 0.7 \\
\hline Others & 19 & 4.3 & 24 & 5.5 \\
\hline \multicolumn{5}{|l|}{ Education } \\
\hline Primary & 312 & 71.2 & 53 & 12.1 \\
\hline Secondary and higher & 45 & 10.3 & 8 & 1.8 \\
\hline Illiterate & 14 & 3.2 & 6 & 1.4 \\
\hline \multicolumn{5}{|l|}{ Employment status } \\
\hline $\begin{array}{l}\text { Unemployed, student, } \\
\text { and other }\end{array}$ & 329 & 75.1 & 27 & 6.2 \\
\hline Self-employed & 10 & 2.3 & 35 & 8 \\
\hline Employed & 32 & 7.3 & 5 & I.I \\
\hline \multicolumn{5}{|l|}{$\begin{array}{l}\text { Monthly income } \\
\text { (RWF) }\end{array}$} \\
\hline Below 50,000 & 339 & 77.4 & 52 & 11.9 \\
\hline $50,000-100,000$ & 24 & 5.5 & 14 & 3.2 \\
\hline 100,000 and above & 8 & 1.8 & 1 & 0.2 \\
\hline \multicolumn{5}{|l|}{ Area of residence } \\
\hline Nyanza & 366 & 83.6 & 58 & 13.2 \\
\hline Outside Nyanza & 5 & I.I & 9 & 2.1 \\
\hline
\end{tabular}

95\% CI $0.14-0.977 ; p=0.045)$. Those who were married were less likely to have low VMMC uptake of (OR 0.536, $95 \%$ CI $0.326-0.882 ; p=0.014)$ than those who were single (Table 7).

\section{Discussion}

VMMC uptake in Nyanza was $35.8 \%$. This is relatively higher than the national prevalence $(30 \%)$ reported in the 2014/2015 Rwanda Demographic and Health Survey, ${ }^{22}$ but lower than that in other areas such as in north Africa 
Table 6 Bivariate Analysis of VMMC Uptake

\begin{tabular}{|c|c|c|c|c|c|}
\hline \multirow[t]{2}{*}{ Variables } & \multirow{2}{*}{$\frac{\text { Circumcised }}{n}$} & \multicolumn{2}{|c|}{ Uncircumcised } & \multirow[t]{2}{*}{$95 \% \mathrm{Cl}$} & \multirow[t]{2}{*}{$p$} \\
\hline & & $\mathbf{n}$ & OR & & \\
\hline \multicolumn{6}{|l|}{ Age } \\
\hline 18-22 years & 17 & 32 & Ref & & \\
\hline 23-27 years & 32 & 57 & 0.946 & $(0.456,1.964)$ & 0.882 \\
\hline 28-32 years & 28 & 45 & 0.854 & $(0.402, I .8 I 5)$ & $0.68 I$ \\
\hline $33-37$ years & 33 & 54 & 0.869 & $(0.419,1.805)$ & 0.707 \\
\hline $38-42$ years & 24 & 61 & 1.350 & $(0.635,2.87 I)$ & 0.435 \\
\hline 43-49 years & 23 & 32 & 0.739 & $(0.334,1.638)$ & 0.457 \\
\hline \multicolumn{6}{|l|}{ Marital status } \\
\hline Single & 39 & 86 & Ref & & \\
\hline Married & 114 & 180 & 0.72 & $(0.46,1.12)$ & 0.141 \\
\hline Separated/divorced & 4 & 15 & 1.7 & $(0.53,5.46)$ & 0.372 \\
\hline \multicolumn{6}{|l|}{ Religion } \\
\hline Muslim & 9 & 4 & Ref & & \\
\hline Catholic & 127 & 255 & 4.52 & $(1.36,14.95)$ & $0.014^{*}$ \\
\hline Other & 21 & 22 & 2.36 & $(0.63,8.83)$ & 0.203 \\
\hline \multicolumn{6}{|l|}{ Education } \\
\hline Primary & 130 & 235 & Ref & & \\
\hline Secondary and higher & 15 & 38 & 1.4 & $(0.74,2.64)$ & $0.03 *$ \\
\hline Illiterate & 12 & 8 & 0.37 & $(0.15,0.92)$ & $0.034 *$ \\
\hline \multicolumn{6}{|l|}{ Employment status } \\
\hline Unemployed, student, and other & 123 & 233 & Ref & & \\
\hline Self-employed & 18 & 27 & 1.443 & $(0.727,2.866)$ & 0.295 \\
\hline Employed & 16 & 21 & 1.143 & $(0.473,2.762)$ & 0.767 \\
\hline \multicolumn{6}{|l|}{ Monthly income (RWF) } \\
\hline Below 50,000 & 138 & 253 & Ref & & \\
\hline $50,000-100,000$ & 15 & 23 & 0.84 & $(0.42,1.66)$ & 0.61 \\
\hline 100,000 and above & 4 & 5 & 0.68 & $(0.18,2.58)$ & 0.57 \\
\hline \multicolumn{6}{|l|}{ Area of residence } \\
\hline Nyanza & 149 & 275 & Ref & & \\
\hline Outside Nyanza & 8 & 6 & 0.41 & $(0.14,1.19)$ & 0.101 \\
\hline \multicolumn{6}{|l|}{ Knowledge about VMMC } \\
\hline Knowledgeable & 135 & 236 & Ref & & \\
\hline Not knowledgeable & 22 & 45 & 1.17 & $(0.67,2.03)$ & 0.577 \\
\hline
\end{tabular}

Note: ${ }^{*} p \leq 0.05$.

Abbreviation: VMMC, voluntary medical male circumcision; Ref, reference.

$(92 \%)$ and $>62 \%$ found in sub-Saharan Africa. ${ }^{22,27,28}$ A majority of participants were aged 23-27 years, and it was in this group that VMMC uptake was low compared to other age-groups.

VMMC uptake was significantly associated withsociodemographic variables. Religion was significantly associated with low VMMC uptake.This result is supported by similar research indicating that religion was associated with uptake, especially in the uncircumcised, in Kenyan communities. ${ }^{5}$ Catholics were almost 7.2 times more likely to have low VMMC uptake of than Muslims. This finding is similar to other esearch reporting that religion and sociocultural beliefs make for difficulties with VMMC uptake within uncircumcised communities. ${ }^{5}$ Our results revealed that those with no formal education were less likely to have low VMMC uptake than those with primary education. This result is supported by prior research indicating that education had a significant influence on 
Table 7 Multivariate Analysis of the of VMMC Uptake

\begin{tabular}{|c|c|c|c|c|c|c|}
\hline & \multicolumn{3}{|c|}{ Full Model } & \multicolumn{3}{|c|}{ Reduced Model } \\
\hline & OR & $95 \% \mathrm{Cl}$ & $p-v$ & OR & $95 \% \mathrm{Cl}$ & $p-v$ \\
\hline \multicolumn{7}{|l|}{ Age } \\
\hline 18-22 years & Ref. & & & & & \\
\hline $23-27$ years & 0.702 & $(0.230,2.147)$ & 0.54 & & & \\
\hline 28-32 years & 0.45 & $(0.127,1.597)$ & 0.22 & & & \\
\hline $33-37$ years & 0.521 & $(0.145,1.869)$ & 0.32 & & & \\
\hline $38-42$ years & 0.759 & $(0.210,2.748)$ & 0.67 & & & \\
\hline $43-49$ years & 0.463 & $(0.123,1.736)$ & 0.25 & & & \\
\hline \multicolumn{7}{|l|}{ Marital status } \\
\hline Single & Ref. & & & Ref. & & \\
\hline Married & 0.568 & $(0.333,0.969)$ & $0.04 *$ & 0.536 & $(0.326,0.882)$ & $0.014^{*}$ \\
\hline Separated/divorced & 1.448 & $(0.418,5.017)$ & 0.56 & 1.394 & $(0.419,4.634)$ & 0.588 \\
\hline \multicolumn{7}{|l|}{ Religion } \\
\hline Muslim & Ref. & & & Ref. & & \\
\hline Catholic & 7.19 & $(1.742,29.659)$ & $0.01 *$ & 6.035 & $(1.731,21.039)$ & $0.005^{*}$ \\
\hline Other & $2.58 \mathrm{I}$ & $(0.597,11.153)$ & 0.2 & 2.544 & $(0.659,9.820)$ & 0.175 \\
\hline \multicolumn{7}{|l|}{ Education } \\
\hline Primary & Ref. & & & Ref. & & \\
\hline Secondary and higher & 1.425 & $(0.702,2.895)$ & 0.33 & 1.477 & $(0.768,2.84 I)$ & 0.243 \\
\hline No formal education & 0.353 & $(0.126,0.988)$ & $0.05^{*}$ & 0.37 & $(0.140,0.977)$ & $0.045^{*}$ \\
\hline \multicolumn{7}{|l|}{ Employment status } \\
\hline Unemployed, student, and other & Ref. & & & & & \\
\hline Self-employed & 0.876 & $(0.267,2.88 I)$ & 0.83 & & & \\
\hline Employed & 0.812 & $(0.291,2.267)$ & 0.69 & & & \\
\hline \multicolumn{7}{|l|}{ Monthly income (RWF) } \\
\hline Below 50,000 & Ref. & & & & & \\
\hline $50,000-100,000$ & 1.165 & $(0.465,2.919)$ & 0.74 & & & \\
\hline 100,000 and above & 1.046 & $(0.217,5.050)$ & 0.96 & & & \\
\hline \multicolumn{7}{|l|}{ Area of residence } \\
\hline Nyanza district & Ref. & & & & & \\
\hline Outside Nyanza & 0.445 & $(0.123,1.607)$ & 0.22 & & & \\
\hline \multicolumn{7}{|l|}{ Knowledge about VMMC } \\
\hline Knowledgeable & Ref. & & & & & \\
\hline Not knowledgeable & 1.25 & $(0.529,2.953)$ & 0.61 & & & \\
\hline
\end{tabular}

Note: $*_{p} \leq 0.05$.

Abbreviation: VMMC, voluntary medical male circumcision.

circumcision, ${ }^{29}$ and is similar to studies in sub-Saharan countries. ${ }^{12,28,30}$

A majority (84.7\%) of participants were highly knowledgeable. This result was contradicts previous studies, wherein VMMC knowledgea was lower and led to low VMMC uptake. ${ }^{31,32}$ The results of this study revealed no significant association between being knowledgeable and low VMMC uptake. In agreement with prior research, ${ }^{31}$ our results revealed that being married decreased the likelihood of low VMMC uptake compared to those who were single. We found no significant associations among residence, age, or employment status. This challenges earlier researchdocumenting age, type of residence, and employment status to be significant contributing factors to low VMMC uptake. ${ }^{5,33}$ Our results revealed that those with no formal education were less likely to have low VMMC uptake than those who had attended primacy schools, in contrast to research 
indicating that those with formal education were less likely to undergo VMMC. ${ }^{33-35}$

Knowledge about VMMC was not found to be significantly associated with uptake; however, it was found that the majority of the participants were knowledgeable about VMMC in terms of knowing about possible VMMC complications and advantages of VMMC, such as reducing the risk of penile cancer. These results contrast with prior studies documenting that lack of adequate knowledge about VMMC was an important factor in low VMMC uptake in Botswana, heightening the risk of STI and HIV/AIDS spread. ${ }^{5,36}$

\section{Limitations}

The study has several limitations. First, it was limited to those aged 18-49 years. Second, it was vulnerable to bias, because the circumcision status was self-reported and respondents could not provide all circumcision information for various reasons. These expected biases were controlled by safeguarding confidential interviews, and proportional sampling was crucial in enroll a suitable sample size from each of the recruited strata from Nyanza.

\section{Conclusion}

Like other studies conducted in African countries, the current study showed that adults were mostly knowledgeable about VMMC and knew the advantages of VMMC for health. VMMC prevalence in the area was higher than the national figure, while low uptake was associated with religion and education. Accomplishing the high national VMMC targets in Rwanda will be an important contributor to furthering the HIV decline in Nyanza.

We recommend that the Ministry of Health and partnerincrease the accessibility of VMMC through strong awareness and mobilization initiatives in the community of Nyanza. This goal should be achieved by creating more awareness about the safety and quality of services in government health facilities. In addition, providing health education in public and private institutions reinforcing that VMMC reduces female-to-male transmission risk of HIV and prevents STIs could lead to increased uptake of VMMC services in Nyanza. Further research is needed on uptake variables nationwide. There is a need in Rwanda for illuminating the influences of VMMC on STI and HIV prevention, treatment, and care. We recommend further research at a national level.

\section{Abbreviations}

MMC, medical male circumcision; NGO, nongovernmental organization; STIs, sexually transmitted infections; UNAIDS, Joint United Nations Programme on HIV/AIDS; VMMC, voluntary MMC; WHO, World Health Organization.

\section{Data Sharing Statement}

The data sets used in this research are available from the corresponding author. All data generalized or analyzed in this study may be shared upon permission being granted by the corresponding author.

\section{Ethics Approval and Consent to Participate}

Ethics approval with the reference number $\left(\mathrm{N}^{0}: 425 / \mathrm{CMHS}\right.$ IRB/2019) was granted by the Institutional Review Board of the College of Medicine and Health Sciences, University of Rwanda. District authorities provided permission to conduct data collection in their districts. Participants were informed about the aim of the study, and all provided oral and written informed consent. Confidentiality and privacy were preserved by ensuring that the interviews were performed in private spaces comfortable for the participants. Codes for the participants were safeguarded to conceal identities, and the researchers handled all records securely through the use of locked files.

\section{Consent for Publication}

Consent to publish the results from this study was obtained from the participants.

\section{Acknowledgments}

This research could not have been realized without professional support from the School of Public Health (SPH), University of Rwanda. We also send our gratitude to the SPH administration and all lecturers from Community Health Department for their invaluable knowledge and skills. We particularly acknowledge the research participants and data collectors for their contributions.

\section{Author Contributions}

Both authors made a significant contribution to the work reported, whether in conception, study design, execution, data acquisition and interpretation, or in all these areas, took part in drafting, revising, or critically reviewing the article, 
gave final approval to the version to be published, agreed on the journal to which the article has been submitted, and agree to be accountable for all aspects of the work.

\section{Disclosure}

The authors report no conflicts of interest in this work.

\section{References}

1. Bhutta ZA, Sommerfeld J, Lassi ZS, Salam RA, Das JK. Global burden, distribution, and interventions for infectious diseases of poverty. Infect Dis Poverty. 2014;3(1):1-7. doi:10.1186/2049-9957-3-21

2. Ngo VK, Rubinstein A, Ganju V, Kanellis P, Loza N. Grand challenges: integrating mental health care into the non-communicable disease agenda. PLoS Med. 2013;10(5):1-5. doi:10.1371/journal. pmed. 1001443

3. Bailey RC, Plummer FA, Moses S. Male circumcision and HIV prevention: current knowledge and future research directions. Lancet Infect Dis. 2001;1(4):223-231. doi:10.1016/S1473-3099(01)00117-7

4. Herman-Roloff A, Otieno N, Agot K, Ndinya-Achola J, Bailey RC, Badley AD. Acceptability of medical male circumcision among uncircumcised men in Kenya one year after the launch of the national male circumcision program. PLoS One. 2011;6(5):3-8. doi:10.1371/ journal.pone.0019814

5. Chiringa IO, Ramathuba DU, Mashau NS. Factors contributing to the low uptake of medical male circumcision in Mutare Rural District, Zimbabwe. African J Prim Heal Care Fam Med. 2011;8(2):1-6. doi:10.4102/phcfm.v8i2.966

6. Kamath V, Limaye RJ. Voluntary medical male circumcision for HIV prevention and early resumption of sexual activity: a literature review. AIDS Care. 2015;27(8):986-989. doi:10.1080/09540121.20 15.1017797

7. Macintyre K, Andrinopoulos K, Moses N, et al. Attitudes, perceptions and potential uptake of male circumcision among older men in Turkana County, Kenya using qualitative methods. PLoS One. 2014;9 (5):1-7. doi:10.1371/journal.pone.0083998

8. Salud OM de la. World Health Organization. WHO progress brief voluntary medical male circumcision for HIV prevention in priority countries of East and Southern Africa. 2015:2015-2016.

9. Herman-Roloff A, Otieno N, Agot K, Ndinya-Achola J, Bailey R, Badley AD. Acceptability of medical male circumcision among uncircumcised men in Kenya one year after the launch of the national male circumcision program. PLoS One. 2011;6(5):e19814. doi:10.13 71/journal.pone.0019814

10. Gray R, Kigozi G, Serwadda D, et al. Male circumcision for HIV prevention in men in Rakai, Uganda: a randomised trial. Lancet. 2007;369(9562):657-666.

11. Morris BJ, Wamai RG, Krieger JN, Banerjee J, Klausner JD. Male circumcision to prevent syphilis in 1855 and HIV in 1986 is supported by the accumulated scientific evidence to 2015: response to Darby. Glob Public Health. 2017;12(10):1315-1333. doi:10.1080/ 17441692.2015.1104371

12. Rupfutse M, Tshuma C, Tshimanga M, et al. Factors associated with uptake of voluntary medical male circumcision, Mazowe District, Zimbabwe, 2014. Pan Afr Med J. 2014;8688:1-8. doi:10.11604/ pamj.2014.19.337.5245

13. Hajizadeh M, Sia D, Heymann SJ, Nandi A. Socioeconomic inequalities in HIV/AIDS prevalence in sub-Saharan African countries: evidence from the demographic health surveys. Int $J$ Equity Health 2014;13(1):1-22. doi:10.1186/1475-9276-13-18

14. World Health Organization, UNAIDS. Male Circumcision Male Circumcision: Global Trends and Determinants of Prevalence, Safety and Acceptability. 2007.
15. Semo B, Wirth K, Ntsuape C, et al. Modifying the health system to maximize voluntary medical male circumcision uptake: a qualitative study in Botswana. HIV AIDS (Auckl). 2017;10:1-8. doi:10.2147/ HIV.S144407

16. Nagelkerke NJD, Moses S, de Vlas SJ, Bailey RC. Modelling the public health impact of male circumcision for HIV prevention in high prevalence areas in Africa. BMC Infect Dis. 2007;7(1):1-15. doi:10.1186/1471-2334-7-16

17. Auvert B, Taljaard D, Lagarde E, Sobngwi-Tambekou J, Sitta R, Puren A. Randomized, controlled intervention trial of male circumcision for reduction of HIV infection risk: the ANRS 1265 trial. PLoS Med. 2005;2(11):1112-1122. doi:10.1371/journal.pmed.002 0298

18. Kaufman MR, Smelyanskaya M, Lith Van LM, et al. Adolescent sexual and reproductive health services and implications for the provision of voluntary medical male circumcision: results of a systematic literature review. PLoS One. 2016;11(3):e0149892. doi:10.1371/journal.pone.0149892

19. Binagwaho A, Pegurri E, Muita J, Bertozzi S, Kalichman SC. Male circumcision at different ages in Rwanda: a cost-effectiveness study. PLoS Med. 2010;7(1):e1000211. doi:10.1371/journal.pmed.1000 211

20. UNAIDS, World Health Organization. AIDS epidemic update; 2007. Available from: http://data.unaids.org/pub/EPISlides/2007/2007_ epiupdate_en.pdf. Accessed March 17, 2021.

21. Sgaier SK, Reed JB, Thomas A, Njeuhmeli E. Achieving the HIV prevention impact of voluntary medical male circumcision: lessons and challenges for managing programs. PLoS Med. 2014;11(5): e1001641. doi:10.1371/journal.pone.0098221

22. NISR. Rwanda Demographic and Health Survey 2014-15: Final Report. National Institute of Statistics of Rwanda; 2015.

23. Yamane T. Statistics, an Introductory Analysis. Second ed. Harper and Row; 1967.

24. Bluman AG. Elementary Statistics: A Step by Step Approach. Seventh ed. McGraw-Hill; 2009.

25. World Medical Association. WMA declaration of helsinki - ethical principles for medical research involving human subjects; 2011. Available from: https://www.wma.net/policies-post/wma-declarationof-helsinki-ethical-principles-for-medical-research-involving-humansubjects/. Accessed March 17, 2021.

26. World Health Organization (WHO). Declaration of Helsinki word medical association declaration of Helsinki. Bull World Health Organ. 2001;373-374.

27. Williams B, Lloyd-Smith J, Gouws E, et al. The potential impact of male circumcision on HIV in Sub-Saharan Africa. PLoS Med. 2006;3(7):e262. PMC 1489185. doi:10.1371/journal.pmed.0030 262

28. Morris B, Wamai R, Henebeng E, et al. Estimation of country-specific and global prevalence of male circumcision. Popul Health Metr. 2016;14(1):4. doi:10.1186/s12963-016-0073-5

29. Tapera R, Kebofe T, Tumoyagae T, January J. Factors associated with uptake of voluntary medical male circumcision among University of Botswana undergraduate male students. Int $J$ Health Promot Educ. 2017;55(5-6):333-342. doi:10.1080/14635240.2017. 1394796

30. Plotkin M, Castor D, Mziray H, Ku J, Mpuya E, Luvanda J. Man, what took you so long? Social and individual male circumcision services in Tanzania. Glob J Health Sci. 2013;1(1):108-116. doi:10. 9745/GHSP-D-12-00037

31. Mavhu W, Buzdugan R, Langhaug L, et al. Prevalence and factors associated with knowledge of and willingness for male circumcision in rural Zimbabwe. Trop Med Int Health. 2011;16(5):589-597. doi:10.1111/j.1365-3156.2011.02744.x

32. Saye JO. Determinants of voluntary medical male circumcision uptake among adults in Luo Nyanza. Trop Med Int Health. 2012. 
33. Akinyi OF, Submitted R, Partial IN, et al. Factors Influencing Uptake of Voluntary Medical Male Circumcision by Male Adults in Kasipul Sub-County. 2014.

34. Nanteza BM, Serwadda D, Kankaka EN, Mongo GB, Gray R, Makumbi FE. Knowledge on voluntary medical male circumcision in a low uptake setting in northern Uganda. BMC Public Health. 2018;18(1):1-7. doi:10.1186/s12889-018-6158-2

35. Kundi GJ, Mphuru L, McMahan J, et al. Increased uptake of voluntary medical male circumcision (VMMC) services among older men following mobile technology demand creation in Shinyanga and Simiyu, Tanzania. Online J Public Health Inform. 2014;6(1):2579. doi:10.5210/ojphi.v6i1.5118
36. Frajzyngier V, Odingo G, Barone M, Perchal P, Pavin M. Safety of adult medical male circumcision performed by non-physician clinicians in Kenya: a prospective cohort study. Glob J Health Sci. 2014;2 (1):93-102. doi:10.9745/ghsp-d-13-00120

\section{Publish your work in this journal}

HIV/AIDS - Research and Palliative Care is an international, peerreviewed open-access journal focusing on advances in research in HIV, its clinical progression and management options including antiviral treatment, palliative care and public healthcare policies to control viral spread. The manuscript management system is completely online and includes a very quick and fair peer-review system, which is all easy to use. Visit http://www.dovepress.com/testimonials.php to read real quotes from published authors. 